\title{
Decreased adiponectin level in adults with central obesity and low 25-hydroxy vitamin D level
}

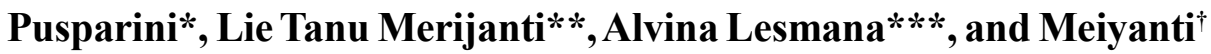

ABSTRACT

\section{BACKGROUND}

Vitamin D insufficiency is associated with obesity and central obesity, which is in turn associated with the accumulation of visceral fat. Visceral fat secretes adiponectin which has a role in the pathogenesis of the metabolic syndrome, diabetes mellitus and cerebrovascular disease. The aim of this study was to determine the relationship between serum 25-hydroxy vitamin $\mathrm{D}[25(\mathrm{OH}) \mathrm{D}]$ level and adiponectin level in adults with central obesity.

\section{METHODS}

This study was a cross sectional study with 80 subjects with central obesity and 80 healthy subjects as controls. The age of the subjects ranged from 55 to 65 years. The data collection included anthropometry and blood biochemistry (lipid profile, fasting blood glucose, $25(\mathrm{OH}) \mathrm{D}$, and adiponectin). The data were analyzed using independent $t$ test with $p$ $<0.05$.

\section{RESULTS}

Mean waist circumference and $25(\mathrm{OH}) \mathrm{D}$ level in the central obesity group were $94.9 \pm 7.8 \mathrm{~cm}$ and $14.3 \pm 6.6 \mathrm{ng} / \mathrm{mL}$, respectively, and in the control group $72.4 \pm 5.0 \mathrm{~cm}$ and $19.2 \pm 8.6 \mathrm{ng} / \mathrm{mL}$ respectively. There were significant differences in adiponectin level between the central obesity group and the control group at the $25(\mathrm{OH}) \mathrm{D}$ level of $<20 \mathrm{ng} / \mathrm{mL}$ ( $\mathrm{p}=0.001$ ), but no significant differences between the two groups at the $25(\mathrm{OH}) \mathrm{D}$ level of $\geq 20 \mathrm{ng} / \mathrm{mL}$ $(\mathrm{p}=0.538)$.

\section{CONCLUSION}

The central obesity subgroup with $25(\mathrm{OH}) \mathrm{D}$ level of $<20 \mathrm{ng} / \mathrm{mL}$ have lower adiponectin levels compared with the control group. This study demonstrates the role of adiponectin as a link between insulin resistance and vitamin D status in adults.

Keywords: Vitamin D deficiency, central obesity, adiponectin, adult
*Department of Clinical Pathology, Faculty of Medicine,

Trisakti University, Jakarta,Indonesia **Department of Occupational Medicine, Faculty of Medicine, Trisakti University, Jakarta, Indonesia ***Department of Clinical Pathology, Faculty of Medicine,

Trisakti University, Jakarta,Indonesia ${ }^{\dagger}$ Department of Pharmacology,

Faculty of Medicine,

Trisakti University, Jakarta, Indonesia

Correspondence :

Prof. Dr. dr. Pusparini, Sp.PK

Department of Clinical Pathology,

Faculty of Medicine,

Trisakti University

J1. Kyai Tapa no 260, Grogol,

Jakarta 11440, Indonesia

Phone: +62-21-5655786,

Fax: +62-21-5660706

Email: pusparini_sppk@yahoo.com

Date of first submission, May 29, 2017

Date of final revised submission,

November 15, 2017

Date of acceptance, November 16 , 2017

This open access article is distributed under a Creative Commons AttributionNon Commercial-Share Alike 4.0 International License

Cite this article as: Pusparini, Merijanti LT, Lesmana A, et al. Decreased adiponectin level in adults with central obesity and low 25-hydroxy vitamin D level. Univ Med 2017;36:205-13. doi: 10.18051/UnivMed.2017.v36.205213 


\section{INTRODUCTION}

Obesity is a global problem in developed as well as developing countries. There was a two-fold increased prevalence of obesity from 1980 up to 2014 . $^{(1)}$ The rapid increase in prevalence of obesity is associated with changes in life style and dietary pattern. Obesity is associated with various disease risk factors such as such as diabetes, hypertension and cardiovascular disease. ${ }^{(2)}$ The initial stage of type 2 diabetes mellitus and the metabolic syndrome is central obesity. Central obesity is the condition of an individual's waist circumference of $\geq 80$ $\mathrm{cm}$ for females for females and $\geq 90 \mathrm{~cm}$ for males according to Asia-Pacific criteria. ${ }^{(3)}$

Adipose tissue is an endocrine organ that secretes a number of proteins known as adipokines. One of the adipokines is adiponectin that is known to play a role in the pathogenesis of the metabolic syndrome. The physiological role of adiponectin is not yet clear. ${ }^{(4)}$ One of several hypotheses that is put forward to clarify the protective role of adiponectin in cardiometabolic disorders is among others that adiponectin has anti-inflammatory effects, increases insulin sensitivity, increases glucose uptake at the cellular level, decreases gluconeogenesis in the liver, and increases the formation of adipocytes. ${ }^{(5-7)} \mathrm{A}$ low adiponectin level is frequently associated with obesity, insulin resistance, hypertension and cardiovascular disease (CVD). ${ }^{(4)}$ A low adiponectin level in the blood also is a strong marker of the probability of the metabolic syndrome and type 2 diabetes mellitus. ${ }^{(7)}$ In obesity there is a change in protein secretion in adipose tissue, such as a decrease in the anti-inflammatory adiponectin, while other adipokines produced by adipose tissue such as tumor necrosis factor $\alpha(\mathrm{TNF}-\alpha)$ and interleukin-6 (IL-6) are increased. ${ }^{(5,6)}$

Obesity is associated with low vitamin D and adiponectin levels and an increase in CVD and mortality. The vitamin D level is associated with the body mass index (BMI) and adiponectin. The higher the BMI of an individual, the lower the vitamin D and adiponectin levels. ${ }^{(8)}$ Vitamin $\mathrm{D}$ deficiency is a common health problem found throughout the world and is found in around one third to one half of the young adult up to the elderly population. ${ }^{(9)}$ The vitamin D level is influenced by exposure to sunlight, seasonal changes, dietary intake, clothing habits, body composition, ethnicity and genetic factors. ${ }^{(6)}$ Vitamin D deficiency is caused by inadequate exposure to sunlight and by a dietary intake that is low in vitamin D. Vitamin D deficiency is most frequently associated with musculoskeletal disorders. In addition, vitamin D deficiency is also one of the risk factors for hypertension, various types of cancer, autoimmune disease, type 2 diabetes mellitus and CVD. ${ }^{(9)}$

The results of the study by Setiati ${ }^{(10)}$ with 74 females as subjects showed a prevalence of vitamin $\mathrm{D}$ deficiency of $31.5 \%$, whereas the results of the study by Green et al. ${ }^{(11)}$ on females aged 18-40 years showed a prevalence of vitamin D deficiency of $63 \%$. The results of these two studies showed that although Indonesia is located in a region with high exposure to sunlight, this does not guarantee the absence of vitamin D deficiency in this country. Vitamin D deficiency contributes to the development of chronic diseases, such as CVD, hypertension and diabetes mellitus. ${ }^{(10)}$

There are many reports of studies on the role of vitamin $\mathrm{D}$ and its relationship with obesity that triggers chronic disease, but the underlying mechanism of this relationship is still a matter of debate particularly on the role of adiponectin. ${ }^{(6)}$ The study of Bidulescu et al. ${ }^{(8)}$ showed that the relationship between vitamin $\mathrm{D}$ and adiponectin levels is influenced by ethnicity, gender, and body mass index (BMI). The study of Foong et al. ${ }^{(12)}$ showed that vitamin D insufficiency is associated with a younger age, gender, abdominal obesity and the metabolic syndrome. ${ }^{(12)}$ The relationship of adipokines with vitamin $\mathrm{D}$ is studied from the aspect of their role in obesity. A meta-analysis on the effect of vitamin D supplementation on adiponectin and leptin levels also could not observe an association among 9 randomized controlled trials. ${ }^{(6)}$ 
For women aged 55-65 years, weight gain and obesity are their major health risks. ${ }^{(13)}$ In a prospective, observational study designed to analyze risk factors for fracture in an ambulatory population aged $>55$ years, $73(88 \%)$ had evidence of osteopenia or osteoporosis (T-score $<-1.5)$ and/or low 25(OH)D. ${ }^{(14)}$

The present study aimed to determine the relationship between $25(\mathrm{OH}) \mathrm{D}$ and adiponectin levels in the serum of adults with central obesity aged 55-65 years.

\section{METHODS}

\section{Research design}

This was a cross-sectional study conducted at Puskesmas Kecamatan Mampang, South Jakarta, from March to June 2014.

\section{Research subjects}

The study subjects consisted of two groups, i.e. 80 subjects with central obesity and 80 healthy subjects without central obesity as controls. The sample size was obtained using the formula:

$\mathrm{n} 1=\mathrm{n} 2=\left[\frac{(\mathrm{Z} \alpha+\mathrm{Z} \beta)}{0.5 \ln \left[\left(1+\mathrm{r}_{1}\right) /\left(1-\mathrm{r}_{1}\right)\right]-\ln \left[\left(1+\mathrm{r}_{2}\right) /\left(1-\mathrm{r}_{2}\right)\right]}\right]^{2}+3$

where $\alpha=5 \%$, for one-sided hypothesis so that $Z \alpha=1.64 ; \beta=10 \%$, so that $Z \beta=1.28 ; r_{1}=r_{2}=$ $0.36{ }^{(8)}$

The minimal sample size was 63 , rounded upwards to 80 . For the control group the number of subjects was also taken as 80 .

Subjects were selected by simple random sampling. The inclusion criteria were: males and females aged 55-65 years, agreeing to participate in this study by signing informed consent, not suffering from stroke and other terminal diseases such as malignancy, renal failure, and myocardial infarction. The exclusion criteria were current consumption of corticosteroids, hormonal replacement therapy, and vitamin D supplements.

\section{Data collection}

Based on the demographic data the elderly study subjects aged $55-65$ years were selected from five kelurahan in Kecamatan Mampang, South Jakarta. Subjects who agreed to participate in this study were asked to give a statement of their willingness to participate by signing informed consent. The questionnaires were filled in by interviewers who had previously been trained with regard to the objectives of the study and the filling in of the questionnaires. The interviewers were cadres at Puskesmas Kecamatan Mampang with an educational level of at least senior high school or equivalent.

\section{Measurements}

The study subjects who met the inclusion and exclusion criteria were asked to come to the study location after an overnight fast of 12 hours before blood collection for laboratory examination. Measurement of blood pressure (with a mercury sphygmomanometer), pulse rate (by stopwatch), temperature, weight, height, and waist circumference, and also blood sample collection were performed by 2 previously trained nurses.

\section{Laboratory analysis}

At baseline, laboratory examinations were performed using venous blood samples of $10 \mathrm{ml}$ each for determination of fasting glucose and lipid profile, while the remaining sera of the blood samples were stored for determination of adiponectin and $25(\mathrm{OH}) \mathrm{D}$. The $25(\mathrm{OH}) \mathrm{D}$ level was determined by indirect competitive chemiluminescence immunoassay (CLIA), ${ }^{(15)}$ while adiponectin level was determined by sandwich immunoassay. ${ }^{(16)}$ Vitamin D deficiency was defined as a serum $25(\mathrm{OH}) \mathrm{D}$ level below $20 \mathrm{ng} / \mathrm{mL}$ or $50 \mathrm{nmol} / \mathrm{L}$. A $25(\mathrm{OH}) \mathrm{D}$ level in the range of $21-29 \mathrm{ng} / \mathrm{mL}(52-72 \mathrm{nmol} / \mathrm{L})$ was designated vitamin $\mathrm{D}$ insufficiency while a level of $\geq 30 \mathrm{ng} / \mathrm{mL}$ was deemed sufficient or normal. ${ }^{(9)}$ The laboratory examinations were performed at Prodia Laboratories, Jakarta. 


\section{Ethical clearance}

The study was performed after approval of the procedure by the Ethical Committee, Faculty of Medicine, Trisakti University, Jakarta, under registration number 51/KER/FK/05/2013. At recruitment specially trained field workers explained the study protocol to the study subjects before requesting their written informed consent.

\section{Statistical analysis}

Tests on the normality of the variable data using the Kolmogorov-Smirnov test showed that the data were normally distributed. The characteristics of the subjects were presented as mean and standard deviation. To evaluate differentiation between $25(\mathrm{OH}) \mathrm{D}$ and adiponectin concentrations in central obesity and control subjects, the independent t-test was used.

\section{RESULTS}

A total of 189 subjects aged 55-65 years agreed to participate in this study, among whom 29 subjects did not meet the inclusion and exclusion criteria, among others 10 subjects who were older than 65 years, 5 subjects who were younger than 55 years, 2 subjects who were consuming blood viscosity reducing agents such as aspirin, 2 subjects who had once suffered from stroke, 1 subject who had liver disorder and 9 who did not appear on the first day of the study. The study respondents who came for physical and laboratory examinations, and met the inclusion and exclusion criteria, were in total 160 subjects, consisting of two groups, i.e. 80 subjects with central obesity and 80 subjects without central obesity (waist circumference less than $80 \mathrm{~cm}$ for females and less than $90 \mathrm{~cm}$ for males) as the control group.

\section{Characteristics of study subjects}

Mean age of the study subjects in both groups were not significantly different, i.e. 59.1 \pm 2.9 years in the central obesity group and 58.8 \pm 2.5 years in the control group. In the central obesity group the majority of subjects were male
$(62.0 \%)$ whereas in the control group the majority of subjects were female $(52.9 \%)$. The most frequent educational level in the central obesity group was senior high school (34.2\%) whereas in the control group the levels were elementary school and senior high school (29.4\%). The majority of subjects were still employed, i.e. $53.2 \%$ in the central obesity group and $64.7 \%$ in the control group. In the central obesity group the mean waist circumference of the males and females were $95.1 \pm 7.2 \mathrm{~cm}$ and $94.9 \pm 8.3 \mathrm{~cm}$, respectively, which was significantly different with the control group, where the mean waist circumference of the males was $71.5 \pm 4.8 \mathrm{~cm}$ and that of the females $73.5 \pm 5.4 \mathrm{~cm}(\mathrm{p}=0.000)$. Mean BMI in the central obesity group was $27.2 \pm 3.4 \mathrm{~kg} / \mathrm{m}^{2}$, being significantly different with the mean BMI of the control group of $20.9 \pm 2.2 \mathrm{~kg} / \mathrm{m}^{2}$ $(\mathrm{p}=0.000)$. Mean systolic blood pressure in the central obesity group was $136.5 \pm 21.3 \mathrm{mmHg}$, being significantly different with that of the control group of $114.1 \pm 13.4 \mathrm{mmHg}(\mathrm{p}=0.000)$. Daily dietary intake of vitamin D was not significantly different between the central obesity group and the control group. The demographic data of the study subjects can be seen in Table 1.

\section{Biochemical parameters}

Lipid profile, i.e. the levels of total cholesterol, HDL cholesterol and LDL cholesterol was not significantly different between the central obesity group and the control group, except for the triglyceride level $(p=0.027)$. Mean triglyceride level in the control group was lower than in the central obesity group $(95.6 \pm 45.8 \mathrm{mg} / \mathrm{dL}$ vs $152.5 \pm 77.7 \mathrm{mg} / \mathrm{dL})$. The vitamin $\mathrm{D}$ level in the central obesity group was significantly lower compared with the control group ( $\mathrm{p}=0.013)$. The most frequent vitamin $\mathrm{D}$ level in both groups was $<20 \mathrm{ng} / \mathrm{mL}$, the percentages being $86.2 \%$ and $52.9 \%$, respectively, in the central obesity group and the control group $(\mathrm{p}=0.000)$. The adiponectin level in the central obesity group was $4.7 \pm 0.26 \mathrm{ng}$ / 
Table 1. Distribution of sociodemographic characteristics and clinical features in the two groups

\begin{tabular}{|c|c|c|c|}
\hline Characteristic & $\begin{array}{c}\text { Central obesity } \\
(\mathbf{n}=\mathbf{8 0})\end{array}$ & $\begin{array}{c}\text { Controls } \\
(\mathbf{n}=\mathbf{8 0})\end{array}$ & p value \\
\hline Age (years) & $59.1 \pm 2.9$ & $58.8 \pm 2.5$ & 0.684 \\
\hline \multicolumn{4}{|l|}{ Gender $[\mathrm{n}(\%)]$} \\
\hline Female & $31(38.0)$ & $42(52.9)$ & 0.259 \\
\hline Male & $49(62.0)$ & $38(47.1)$ & \\
\hline \multicolumn{4}{|l|}{ Education $[\mathrm{n}(\%)]$} \\
\hline Did not attend school & $6(6.3)$ & $0(0)$ & \\
\hline Did not finish elementary school & $11(13.9)$ & $14(17.6)$ & \\
\hline Elementary school & $22(27.6)$ & $24(29.4)$ & 0.708 \\
\hline Junior high school & $12(15.2)$ & $19(23.5)$ & \\
\hline Senior high school & $27(34.2)$ & $23(29.4)$ & \\
\hline Academy/tertiary education & $1(1.3)$ & $0(0)$ & \\
\hline \multicolumn{4}{|l|}{ Employment status [n (\%)] } \\
\hline Employed & $38(46.8)$ & $28(35.3)$ & \\
\hline Non-employed & $42(53.2)$ & $52(64.7)$ & 0.763 \\
\hline Waist circumference $(\mathrm{cm})$ & $94.9 \pm 7.8$ & $72.4 \pm 5.0$ & $0.000 *$ \\
\hline Males & $95.1 \pm 7.2$ & $71.5 \pm 4.8$ & $0.000 *$ \\
\hline Females & $94.9 \pm 8.2$ & $73.5 \pm 5.4$ & $0.000^{*}$ \\
\hline Hip circumference (cm) & $98.3 \pm 7.5$ & $88.0 \pm 5.9$ & $0.000 *$ \\
\hline Weight (kg) & $65.3 \pm 10.2$ & $49.8 \pm 6.2$ & $0.000 *$ \\
\hline Height $(\mathrm{cm})$ & $154.8 \pm 6.9$ & $154.1 \pm 8.6$ & 0.731 \\
\hline Body mass index $\left(\mathrm{kg} / \mathrm{m}^{2}\right)$ & $27.2 \pm 3.4$ & $20.9 \pm 2.2$ & $0.000 *$ \\
\hline Systolic blood pressure $(\mathrm{mmHg})$ & $136.5 \pm 21.3$ & $114.1 \pm 13.4$ & $0.000 *$ \\
\hline Diastolic blood pressure $(\mathrm{mmHg})$ & $84.2 \pm 10.7$ & $70.0 \pm 6.4$ & $0.000 *$ \\
\hline Pulse rate (per minute) & $77.0 \pm 10.0$ & $77.9 \pm 11.3$ & 0.749 \\
\hline \multicolumn{4}{|l|}{ Nutrient intake/day } \\
\hline Energy (Kcal) & $1866 \pm 566.2$ & $1675 \pm 553.1$ & $0.000^{*}$ \\
\hline Carbohydrate (g) & $326.5 \pm 101.7$ & $275.6 \pm 97.5$ & $0.000 *$ \\
\hline Protein $(g)$ & $38.7 \pm 18.5$ & $38.3 \pm 17.9$ & 0.873 \\
\hline Fat $(\mathrm{g})$ & $58.7 \pm 33.4$ & $54.6 \pm 31.2$ & 0.789 \\
\hline Vitamin D (mg) & $6.5 \pm 2.4$ & $6.6 \pm 2.3$ & 0.832 \\
\hline
\end{tabular}

${ }^{*} \mathrm{p}<0.05$ significance (independent t-test). Data presented as mean $\pm \mathrm{SD}$, except for gender, education and employment

$\mathrm{mL}$, which was significantly lower compared with that in the control group of $6.8 \pm 0.72 \mathrm{ng} /$ $\mathrm{mL}(\mathrm{p}=0.003)$ (Table 2). The present study found vitamin $\mathrm{D}$ deficiency in 111 subjects $(69.4 \%)$ in both groups combined.

\section{Adiponectin levels in vitamin $D$ central obesity subgroups}

Table 3 shows adiponectin levels in the vitamin D level subgroups of $<20 \mathrm{ng} / \mathrm{mL}$ and $\geq 20 \mathrm{ng} / \mathrm{mL}$. The higher the vitamin D level the

Table 2. Biochemical parameters in the central obesity and control groups

\begin{tabular}{lccc}
\hline Biochemical parameter & $\begin{array}{c}\text { Central obesity } \\
(\mathbf{n}=\mathbf{8 0})\end{array}$ & $\begin{array}{c}\text { Control } \\
(\mathbf{n}=\mathbf{8 0})\end{array}$ & p value \\
\hline Lipid profile & $202.3 \pm 34.3$ & $205.9 \pm 41.6$ & 0.776 \\
Total cholesterol (mg/dL) & $152.5 \pm 77.7$ & $95.6 \pm 45.8$ & $0.027^{*}$ \\
Triglycerides (mg/dL) & $47.7 \pm 8.9$ & $53.3 \pm 7.7$ & 0.074 \\
HDL cholesterol (mg/dL) & $133.9 \pm 31.6$ & $142.8 \pm 34.1$ & 0.431 \\
LDL cholesterol (mg/dL) & $108.1 \pm 55.3$ & $95.5 \pm 28.8$ & 0.409 \\
Fasting glucose (mg/dL) & $14.3 \pm 6.6$ & $19.2 \pm 8.6$ & $0.013^{*}$ \\
Vitamin D (ng/mL) status [n, \%)] & $69(86.2)$ & $42(52.9)$ & $0.000^{*}$ \\
$<20$ ng/mL & $11(13.8)$ & $38(47.1)$ & \\
$\geq 20 \mathrm{ng} / \mathrm{mL}$ & $4.7 \pm 0.26$ & $6.8 \pm 0.72$ & $0.003^{*}$ \\
\hline Adiponectin (ng/mL)
\end{tabular}

${ }^{*} \mathrm{p}<0.05$ significance (independent t-test). Data presented as mean \pm SD except for vitamin D status 
Table 3. Adiponectin by 25(OH)D level and central obesity

\begin{tabular}{lccc}
\hline \multirow{2}{*}{ Parameter } & \multicolumn{2}{c}{ Adiponectin } & \multirow{2}{*}{ p value } \\
\cline { 2 - 3 } & $\begin{array}{c}\text { Central obesity } \\
\mathbf{n}=\mathbf{8 0}\end{array}$ & $\begin{array}{c}\text { Control } \\
\mathbf{n}=\mathbf{8 0}\end{array}$ & \\
\hline $25(\mathrm{OH}) \mathrm{D}(\mathrm{ng} / \mathrm{mL})$ & & & $0.001^{*}$ \\
$<20$ & $4.4 \pm 0.23$ & $6.5 \pm 0.9$ & 0.538 \\
$\geq 20$ & $5.8 \pm 0.9$ & 0.9 & \\
\hline
\end{tabular}

${ }^{*} \mathrm{p}<0.05$ significance (independent t-test); Data presented as mean \pm SD

higher also the adiponectin level. This was seen in both the central obesity group and the control group. In the central obesity subgroup with vitamin D level of $<20 \mathrm{ng} / \mathrm{mL}$, the adiponectin levels were significantly lower than in the control group $(\mathrm{p}=0.001)$, whereas in subjects with vitamin D levels of $\geq 20 \mathrm{ng} / \mathrm{mL}$ there was no significant difference in adiponectin levels between the central obesity and control groups $(\mathrm{p}=0.538)$.

\section{DISCUSSION}

Our study results showed a relatively high prevalence of vitamin D deficiency, i.e. $69.4 \%$ in all subjects involved in this study. Vitamin D deficiency was $86.2 \%$ in the central obesity group and $52.9 \%$ in the control group. Our study results showed significantly lower levels of vitamin D in subjects of the central obesity group compared with those in the controls. Both groups showed a mean vitamin D level below $20 \mathrm{ng} /$ $\mathrm{mL}$ which denotes vitamin $\mathrm{D}$ deficiency according to the criteria used by Holick. ${ }^{(9)}$ The prevalence of vitamin D deficiency of $69.4 \%$ in the present study was similar to the study results of Al-Dabhani et al. ${ }^{(17)}$ i.e. $64 \%$. AlDabhani et al. ${ }^{(17)}$ conducted a study on 1205 subjects consisting of 702 females and 503 males, with mean age of $39.9 \pm 10.9$ years. The study of Al-Dabhani et al. ${ }^{(17)}$ also found in subjects with the metabolic syndrome lower serum vitamin D levels compared with the nonmetabolic syndrome group. ${ }^{(17)}$ The same was also reported by Shafinaz et al. ${ }^{(18)}$ in Kuala Lumpur, Malaysia, who found that $67.4 \%$ of adult females with mean age of $48.5 \pm 5.2$ years had vitamin D levels below $20 \mathrm{ng} / \mathrm{mL} .{ }^{(18)}$ The study by Zhen et al. ${ }^{(19)}$ in China on subjects aged $40-75$ years showed that $75.2 \%$ subjects had vitamin D levels of $<20 \mathrm{ng} / \mathrm{mL}$. ${ }^{(19)}$ Indonesia is country that is located at the equator where sunlight is nearly always available throughout the year, so that no vitamin $\mathrm{D}$ deficiency is expected to be found or at most at a very low prevalence compared with Western countries where continuous sunlight is not always. Regarding the habits associated with exposure to sunlight, the majority of subjects answered that they are exposed to sunlight in the morning (data not shown). The daily duration of exposure to sunlight was mostly 10-15 minutes for the central obesity group $(33.7 \%)$ and $>15$ minutes for the control group (31.25\%). In addition, it was also seen that the time of exposure to sunlight was mostly from 8 to $8.30 \mathrm{AM}$ for the central obesity group and from 7 to $7.30 \mathrm{AM}$ for the control group. This shows that the majority of subjects are still of the opinion that the best sunlight is in the morning, although the study of Holick et al..$^{(9)}$ showed that exposure to sunlight from $10 \mathrm{AM}$ to $13 \mathrm{PM}$ twice weekly for 5-30 minutes on the arms and legs was adequate for the daily requirement of vitamin D. The use of tightly covered clothing was found in only $22.5 \%$ of the central obesity group and in $25 \%$ of the control group. Sunblocking agents were also not much used by the subjects of our study, so that presumably the vitamin D deficiency was mostly due to inadequate exposure to sunlight. In the present study there was no significant difference in dietary vitamin D intake between the central obesity group and the control group and both groups tended to have a dietary intake of low vitamin D content, so that the most of the vitamin $\mathrm{D}$ was obtained from 
exposure to sunlight. Food sources rich in vitamin $\mathrm{D}$, such as salmon, tuna, and mackerel are not frequently consumed by Indonesians.

Mean vitamin D levels of the subjects with central obesity was lower than those in the control group. This is in line with the results of the study by Johnson et al. ${ }^{(20)}$ who reported that subjects with obesity had low levels of vitamin $\mathrm{D}$, particularly in the males compared with the females, with an odds ratio of 1.41 (95\% CI: 1.171.70). Other studies that showed low levels of vitamin $\mathrm{D}$ in subjects with obesity were among others the studies conducted by Shafinaz et al., ${ }^{(18)}$ Oommen et al., ${ }^{(21)}$ and Tosunbayraktar et al. ${ }^{(22)}$

In our study we found a mean adiponectin level of $4.7 \pm 0.26 \mathrm{ng} / \mathrm{mL}$ in subjects with central obesity, which was significantly lower than the mean adiponectin level of $6.8 \pm 0.72 \mathrm{ng} / \mathrm{mL}$ in the control group. This showed that subjects with central obesity had lower adiponectin levels compared with the controls. Adiponectin is also known by the name of adipocyte complement related protein of $30 \mathrm{kDa}$, which is secreted by adipose tissue. Adiponectin may activate peroxisome proliferator-activated receptor $\alpha$ (PPAR- $\alpha$ ), stimulate oxidation of free lipids and decrease the triglyceride content of muscular tissue. In the liver, it is only the intact adiponectin molecule that activates adenosine mono phosphate kinase (AMPK) that further reduces the molecules involved in gluconeogenesis and increases the phosphorylation of acetyl coenzyme carboxylase (ACC) and oxidation of fatty acids. Adiponectin activates PPAR- $\alpha$ then stimulates the oxidation of fatty acids and decreases the triglyceride content of the liver. All these changes increase the in vivo insulin sensitivity. ${ }^{(23)}$ The triglyceride levels in the controls was significantly lower than those in the central obesity group. This shows that in the control group a low adiponectin level was associated with a high triglyceride level, and vice versa, a high level of adiponectin was associated with a low triglyceride level.

Adiponectin is one of several adipokines that are produced by mature adipocytes. Adiponectin aids the uptake of glucose and oxidation of free fatty acids in muscle and inhibits gluconeogenesis in the liver, so increasing insulin sensitivity. The level of adiponectin is low in individuals with obesity. ${ }^{(24)}$ The study of a relationship between vitamin $\mathrm{D}$ and adiponectin levels is due to several causes; first, vitamin D receptors are present on preadipocytes so that there is the possibility that $1,25(\mathrm{OH})_{2} \mathrm{D}$ regulates the expression of the adiponectin gene. ${ }^{(25)}$ Second, $25(\mathrm{OH})_{2} \mathrm{D}$ is a hormone that is thought to play a role in the regulation of tumor necrosis factor $\alpha(\mathrm{TNF}-\alpha)$ production. TNF- $\alpha$ is a factor that plays a important role in the synthesis of adiponectin. ${ }^{(6,11,26)}$

Our study results showed that in the control group the adiponectin levels were significantly higher compared with the central obesity group. In the vitamin D subgroups of $<20 \mathrm{ng} / \mathrm{mL}$ and $\geq 20 \mathrm{ng} / \mathrm{mL}$, the adiponectin levels in the control group were higher compared with the central obesity group. These results agree with those of a study by $\mathrm{Si}$ et al. ${ }^{(27)}$ on elderly aged above 65 years, showing that adiponectin levels were higher in the group of patients without the metabolic syndrome compared with patients with the metabolic syndrome. In the aforementioned study it was concluded that the most influential factors on adiponectin levels were BMI, waist circumference, waist to hip ratio, visceral fat, visceral fat ratio and 2 hour insulin levels. ${ }^{(28)}$ The study results of Wang et al. ${ }^{(28)}$ who carried out a study on 3,193 subjects aged 50-70 years showed that adiponectin levels were negatively correlated in the subjects with the metabolic syndrome.

A limitation of this study is the crosssectional study design, so that this study cannot clarify any cause-and-effect relationship. There is a need for an experimental study with subjects who receive adequate exposure to sunlight and do not use vitamin D supplementation, to determine the role of adiponectin in connection with the low levels of vitamin $D$ in subjects with central obesity. The present study showed a prevalence of vitamin D deficiency and insufficiency in the study subjects that was higher than $61.6 \%$. This indicates the need for education 
on the importance of exposure to sunlight, particularly in subjects with central obesity and on the increased awareness of the community about low levels of vitamin D in the majority of the present study subjects, although Indonesia is a country with high exposure to sunlight. Further investigations are needed to better understand the role of vitamin $\mathrm{D}$ in the occurrence of central obesity.

\section{CONCLUSION}

The level of adiponectin in central obesity with $25(\mathrm{OH}) \mathrm{D}$ level of $<20 \mathrm{ng} / \mathrm{mL}$ was lower compared with the control group in adults. Early detection of 25(OH)D and adiponectin levels can prevent the increasing risk of cardiovascular disease.

\section{CONFLICT OF INTEREST}

All authors have disclosed any actual or potential competing interests regarding the submitted article and the nature of those interests.

\section{ACKNOWLEDGEMENTS}

We thank the participants in this study for their cooperation. This study was supported by the Faculty of Medicine, Trisakti University, Jakarta, Indonesia

\section{CONTRIBUTORS}

$P$ and LTM contributed to the design of the study. P, LTM, M, and A contributed to collection of samples and data. P and LTM analyzed and interpreted the data and performed statistical analysis. P, LTM, M, and A contributed to drafting and revising the manuscript. All authors read and approved the final manuscript.

\section{REFERENCES}

1. James WP. The epidemiology of obesity: the size of the problem. J Intern Med 2008;263:336-52.
2. Zhang P, Wang R. Gao C, et al. Prevalence of central obesity among adults with normal BMI and its association with metabolic diseases in northeast China. Plos One 2016;11:e0160402. doi: 10.1371/jounal.pone.0160402.

3. Singla P, Bardolol A, Parkash AA. Metabolic effects of obesity: a review. World J Diab 2010;1: 76-88.

4. Zhang J, Kho P, Kuliesh OV, et al. Adiponectin, resistin and leptin : possible markers of metabolic syndrome. Endocrinol Metab Syndr 2015;4:212. doi: 10.4172/2161-1017.1000212.

5. Huang FY, del Rio Navarro BE, Perez-Ontiveros JA, et al. Effect of six month lifestyle intervention on adiponectin, resistin and soluble tumor necrosis factor $-\alpha$ receptors in obese adolescents. Endocr J Adv Pub 2014. doi: 10.1507/endocrj. EJ14-0157.

6. Hamid Mehmood ZTN, Papandreaou D. An updated mini review of vitamin D and obesity: adipogenesis and inflammation state. J Med Sci 2016;15:526-32.

7. Jaramillo PL. The role of adiponectin in cardiometabolic diseases: effects of nutritional interventions. J Nutr 2016;146:422S-6S.

8. Bidulescu A, Morris AA, Stoyanova N, et al. Association between vitamin $\mathrm{D}$ and adiponectin and its relationship with body mass index: the meta health study. Front Pub Health 2014;2:193. doi: 10.3389/fpubh.2014.00193.

9. Holick M. Vitamin D deficiency. N Engl J Med 2007;357:266-81.

10. Setiati S. Pengaruh sinar ultraviolet B matahari terhadap konsentrasi vitamin D dan hormone parathyroid pada perempuan usia lanjut Indonesia. J Kes Masy Nas 2008;2:147-53.

11. Green TJ, SkeaffCM, Rockell JEP, et al. Vitamin D status and its association with parathyroid hormone concentration in women of child bearing age living in Jakarta and Kuala Lumpur. EJCN 2008;62:373-8.

12. Foong MM, Bulgiba A. High prevalence of vitamin D insufficiency and its association with obesity and metabolic syndrome among Malay adults in Kuala Lumpur, Malaysia. BMC Public Health 2011;11:735. http://www.biomedcentral. com/1471-2458/11/735.

13. Friedenreich CM, Biel RK, Lau DCW, et al. Case control study of the metabolic syndrome and metabolic risk factors for endometrial cancer. Epidemiol Biomarkers Prev 2011;20:2384-95.

14. Seton M, Jackson V, Lesser KE, et al. Low 25hydroxyvitamin $\mathrm{D}$ and osteopenia are prevalent in persons $>$ or $=55 \mathrm{yr}$ with fracture at any site: a prospective, obeservational study of persons 
fracturing in the community. J Clin Densitom 2005; 8:454-60.

15. Enko D, Kriegshauser, Stolba R, et al. Method evaluation study of a new generation of vitamin D assays. Biochem Med 2015;25:203-12.

16. Liu D, Schuster T, Baumann M, et al. Comparison of immunoassays for the selective measurement of human high molecular weight adiponectin. Clin Chem 2009;55:568-72.

17. Al-Dabhani K, Tsilidis KK, Murphy N, et al. Prevalence of vitamin D deficiency and association with metabolic syndrome in a Qatari population. Nutrition \& Diabetes 2017;7:e263. doi: 10.1038/nutd.2017.14.

18. Shafinaz ID, Moy FM. Vitamin D level and its association with adiposity among multi ethnic adults in Kuala Lumpur, Malaysia: a cross sectional study. BMC Public Health 2016;16:232. doi: 10.1186/s12889-016-2924-1.

19. Zhen DH, Liu LJ, Guan CH, et al. High prevalence of vitamin $\mathrm{D}$ deficiency among middle-age and elderly individuals in northwestern China: Its relationship to osteoporosis and lifestyle factors. J Bone 2015;71. doi: 10.1016/j.bone.2014.09.024.

20. Johnson LK, Hofso D, Aasheim ET, et al. Impact of gender on vitamin D deficiency in morbidly obese patients: a cross sectional study. Eur J Clin Nutr 2012;66:83-90.

21. Oommen A, Al Zahrani IH. Association of obesity with vitamin $\mathrm{D}$ deficiency and the clinical implications. Int J Res Med Sci 2015;3:3262-5.
22. Tosunbayraktar G, Bas M, Kut A, et al. Low serum $25(\mathrm{OH}) \mathrm{D}$ levels are associated to higher BMI and metabolic syndrome parameter in adult subjects in Turkey. Afri Health Sci 2015;15:1161-9.

23. Norman AW. Mini review: vitamin D receptor new assignments for an already busy receptor. Endocrinology 2006;147:5542-8. doi: 10.1210/ en.2006-0946.

24. Liu E, Meigs JB, Pittas AG, et al. Plasma 25hydroxyvitamin $\mathrm{D}$ is associated with markers of the insulin resistant phenotype in nondiabetic adults. J Nutr 2009; 139:329-34.

25. Lee S, Lee DK, Choi E, et al. Identification of functional vitamin $\mathrm{D}$ response element in the murrine Insig-2 promoter and its potential role in the differentiation of 3T3-L1 preadipocytes. Mol Endocrinol 2005; 19:399-408.

26. Wimalawansa SJ. Vitamin D deficiency is a surrogate marker for visceral fat content, metabolic syndrome, type 2 diabetes, and future complications. J Diabetes Metab Disord Control 2016;3:00059. doi: 10.15406/jdmdc.2016.03.00059.

27. Si EK, Yea EK, Kyong HY, et al. Plasma adiponectin levels in elderly patients with prediabetes. Endocrinol Metab 2015;30:326-33. doi: 10.3803/ EnM.2015.30.3.326.

28. Wang J, Li HX, Franco OH, et al. Adiponenctin and metabolic syndrome in the middle-aged and elderly Chinese. Obesity 2008;16:172-8. doi: 10.1038/oby2007.42. 